\title{
Important Applications and the Perceived Benefits of Bamboo: A Comparison between Consumers and Businessmen
}

\author{
Daphney Francois ${ }^{1} \&$ Shu-Yi Liaw ${ }^{2}$ \\ ${ }^{1}$ Department of International Master's Degree Program in Agribusiness Management, National Pingtung \\ University of Science and Technology, Pingtung City, Taiwan \\ ${ }^{2}$ Management College, Computer Centre, National Pingtung University of Science and Technology, Pingtung \\ City, Taiwan
}

Correspondence: Shu-Yi Liaw, Management College, Computer Centre, National Pingtung University of Science and Technology, Pingtung City, Taiwan. E-mail: syliaw@mail.npust.edu.tw

Received: February 17, 2019

doi:10.5539/ijbm.v14n6p12
Accepted: April 15, $2019 \quad$ Online Published: May 13, 2019

URL: https://doi.org/10.5539/ijbm.v14n6p12

\begin{abstract}
Bamboo is a versatile product, including building materials, furniture, fencing, handicrafts, pulp and paper, edible shoots, and animal feed used in many countries. The first purpose of this study was to evaluate and group the applications and benefits of bamboo, the second is to compare the views of consumers and businessmen to find the expectation gap between them, the third is to find the correlation between the importance of bamboo applications with the perceived benefit of bamboo and finally apply the importance-performance analysis model to position the expected application and benefits of bamboo. The theory was developed taking in account three factors: the importance, the benefits of bamboo applications, and both consumers and businessmen. The data analysis was performed on a sample of 469 respondents divided into two parts 378 for consumers and 91 for businessmen conducted in Haiti. This study exhibited that the applications were formed two groups - High importance group with five applications represented $48.9 \%$; and the low importance group with 15 applications are represented $51.1 \%$ based in their frequency. Furthermore, the results indicated that the consumer's views were higher than businessman for the important applications of bamboo and the businessmen were higher than the consumers for the perceived benefits of bamboo because the consumers focus on the wants of application can be profitable for us and businessman focus on the benefit. The results showed a positive relationship between the importance of bamboo with the perceive benefits. The study found the most important application is (G) bamboo panels (wall room) from consumers because this application was with multiple purposes; and the fabrication and wood base in the industry from the businessmen. So we might say the applications bamboo was very important for the country according to the respondent's responses and also the benefits for the businessmen. Therefore, if the country could embrace this alternative, it will be a great opportunity for the population.
\end{abstract}

Keywords: bamboo applications, perceive benefits, investment, importance performance analysis (IPA)

\section{Introduction}

Bamboo is considered one of the oldest tools used to build almost anywhere in the world. The processing of bamboo stems can produce a variety of products ranging from household items to industrial applications and others. Bamboo products may include foods such as skewers, baguettes, craft products, furniture, pulp and paper, toys, flooring, charcoal music, boats, and weapons. Taxonomically, it is a group of plants that belong to the subfamily Bambusoideae and family Gramineae. There are more than 1,500 species and 87 kinds of bamboo in the world (Ben-Zhi, Mao-Yi, Jin-Zhong, Xiao-Sheng, \& Zheng-Cai, 2005). Among many countries that use bamboo, their total forest area has decreased considerably; that the area of the bamboo forest has gradually increased. Today China has about 500 species and 39 genera, including the richest bamboo resources in the world in the number of species, areas, and bamboo reserves. That's why; China is nicknamed "the kingdom of bamboo". However, after more than 50 years, the founding of the Republic has become more popular in China, with its economic reforms of China, those that involve for 20 years the increase of the bamboo industry which has developed very rapidly. So this leads to a steady increase in bamboo based on the area of the forests that reach today 5 million $\mathrm{hm}^{2}$. (Ben-hi et al., 2005). Bamboo is considered one of the fastest-growing plants in the world, with a growth rate of 30 to $100 \mathrm{~cm}$ per day during the growing season. It can reach a height of $36 \mathrm{~m}$ and a diameter of 1 to $30 \mathrm{~cm}$ (United Nations 
1972). Stubble reaches its maximum height in two to three months. By referring to these characteristics, it is easy to believe that bamboo is both a renewable resource and the most efficient growth (Sulaiman et al., 2006). Bamboo is an ideal economic investment that can be used in many different ways based on a variety of beneficial applications, so it has a huge potential to alleviate many environmental and social problems that the world today overcomes. The increase in tropical deforestation makes the search for natural resources alternately important. Bamboo can be considered as an ideal solution based on its characteristics for the environment and deforestation as well as for economic and social tropical problems. However, compared to other bamboo growing countries, additionally, its qualities of strength, light weight and flexibility make it a viable alternative to tropical timbers that typically supply the furniture and building materials industries. Haiti is not getting equivalent economic advantage from this resource. The competitiveness of Haiti's bamboo product in the international market does almost not exist. Furthermore, Haiti is vulnerable to natural disasters such as hurricanes, slides, flood, storms, and other disasters such as earthquakes. Considering the different problems that the country faces today, we may consider the benefits of bamboo applications as a form of development for the country on different points. We consider whether the Haitian government is investing and encouraging bamboo planting, the country may export the products to other countries; given bamboo grows more easily in the tropical and subtropical countries and Haiti is a tropical country. In general, with the development of bamboo in terms of different points, we can have another source of energy especially for the population living in rural areas of the country. The adoption of bamboo in Haiti can help the country to eradicate the phenomenon of tents, and give the population the means of housing; and finally, we can say the bamboo plantations can reduce erosion, deforestation, and increase reforestation. We can have fewer deaths in natural disasters; and lastly, with filtration of drinking water, we can reduce the rate of cholera in Haiti.

The motivation of this study was to highlight how the businessmen can invest in bamboo for a developing country; therefore, the growing bamboo can be an option of sustainable for social in environmental practices. Despite of its durability, the marriage between the economic, social, political and ecological systems established over a prolonged period (Cerling, 1992; Thwe \& Liao, 2003). To have a more responsible and sustainable bamboo industry, we need to know the species and its common applications; and also have better methods to increase production and use especially in the country. Over the past few years, bamboo is widely cultivated with exceptional values and most top substitutes for wood. The Bamboo might replace the wood in many industrial applications; thus, it can also increase to economy and deforestation. From this, to highlight the social and environmental benefits, the technology of the related plants, the different applications such as, food cooking, flooring, musical instruments and supplies, construction, plywood, raw materials, purification of drinking water, soil protection - and to emphasize its economic, agricultural, and cultural advantages, by evaluating its benefits that may interest both national and international businessmen to invest their money in bamboo. The objectives of this study are to:

1) evaluate and group the importance of different applications of bamboo and the perceived benefits of the bamboo

2) compare the consumer and businessman views to find the expectation gap

3) find the correlation between the importance of bamboo applications and the perceive benefits of bamboo

4) apply the importance performance analysis (IPA) model to position the expected applications and benefit of bamboo in Haiti.

\section{Theoretical Background and Hypotheses Development}

This study proposed the framework shown in Figure 1. Three hypotheses are drawn from ten (10) attributes, namely, the importance of bamboo has five criteria: profitability (Gielis, Oprins, El Bassam, Behl, \& Prochnow), feasibility (Fea), acceptable (Acc), available (Ava), success (Suc), and the perceived benefit has also five (5) criteria: economic (Eco), social (Soc), environmental (New York State Department of Environmental Conservation), technologic (Tech) and security (EUROBATS Secretariat), the consumer views and businessmen views. 


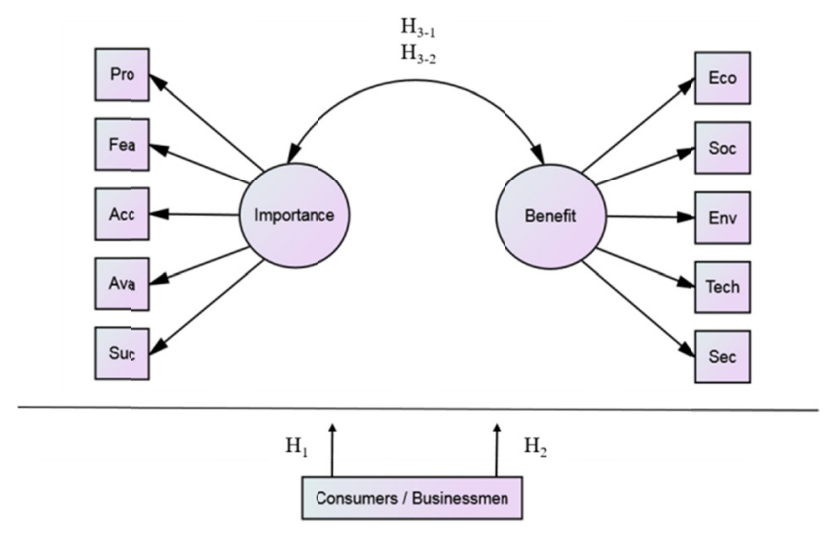

Figure 1. Conceptual model

\subsection{Bamboo and Its Characteristics}

Bamboo has become one of the most important materials in pre-industrial architecture in Asia and South American countries, used as a structural element (Sen \& Reddy, 2011). According to its biological characteristics and its usual growth, bamboo is considered an ideal economic investment that can be used in many different ways, but it has generally a very considerable potential to mitigate many of the social, environmental problems facing the world today. Among the functions such as soil erosion, water conservation, land reclamation and carbon sequestration is very common. The bamboo normally use in construction is mostly available in tropical and subtropical climatic regions; its growth is rapid by a combination of very high mechanical strength and low specific gravity. However, even today the most modern construction uses bamboo based on an artisanal approach, in construction techniques being reserved for a small group of researchers, engineers, and architects (Liu, Song, Anderson, Chang, \& Hua, 2012). Some studies have already shown that bamboo can select its own weight generated by the wind load. It is considered as materials which are physical and mechanical properties that can be optimally modified, and depending on the constraints. It has been observed on a macroscopic scale that the distances between the nodes (stiffeners), the diameter and the thickness could largely vary from the total length of the bamboo trunk, which means that the thickness of the waist and the volumetric fraction of the fibers increase much more, and becoming more concentrated as the outer shell approaches. Determination of how volumetric fracture thickness variation occurs is necessary to apply bamboo composite materials to the theory, which should allow optimized use of bamboo at engineering sites. According to this variation made by properties, as well as macro and microscopic properties, favors the advanced features of bamboo. Several other studies are also underway on the structural of bamboo structures commonly used by local populations, concerning the improvement of permanent concrete shuttering slabs and reinforced concrete beams and columns. Slab Production corrugated composites based on cement paste reinforced with bamboo cellulose pulp. The cement composition in addition by bamboo pastes are produced by a vacuum pressure process, with the aim of establishing the characteristics of a-useful and easy-to-manufacture material, making it possible to use the machines of the bamboo industry. Bamboo pulp is considered on a large scale in the paper industry. Studies are underway to promote sustainable furniture and new geometric structural forms, as well as bicycles, tricycles and bamboo bodies.

\subsection{The Importance of Application of Bamboo}

Bamboo re are several types of species and different sizes. Bamboo usually grows in of Asian country, Latin America and Africa. Due to its very effective structural and natural design; the hollow and the fibers in the longitudinal direction, less mass of material may be required than in the case of massive section materials and wood. So in terms of bearing mass, as for all tubular elements bamboo functions as an I-shaped cross -section; in each direction, it is loaded, while the other cross sections are the most efficient in one or two directions. The conceptual study of bamboo is also demonstrated that the strength and rigidity of various materials are able to be divided by mass and volume (Chung, Cheng, \& Chang, 2008; Hunter, 2003). Based on its favorable mechanical properties, its great flexibility, its rapid growth rate, bamboo is widely regarded as a building material offering many capable of offering more possibilities. It is generally used in many applications, such as crafts that are very traditional to completely industrialized products. Some other bamboo species can very well be used in support 
structures, as evidenced by the very tall bamboo scaffolding against oriental skyscrapers. Bamboo is also used in paper, food, and energy. The reinforcement of course in the building industry, bamboo plays a very important role in daily life (housing, employment, income, fuel, etc.), especially for the less affluent populations in the tropics. Recently, bamboo has also been found more applications in the West, involving industrial applications as well as in temporary structures. And bamboo is also its use in deforestation and soil conservation.

\subsection{Advantages Benefits of Bamboo}

Nowadays bamboo was traditional as a building material in the tropical and subtropical regions of the world. It is therefore widely used in many forms of construction, especially for housing in rural areas. They are often found in Asia, Africa and Latin America. It can reach about 7.5 to $40 \mathrm{~cm}$ per day, with a world record of $1.2 \mathrm{~m}$ in 24 hours more precisely in Japan. According to several sources, some commercialized bamboo species reach maturity in four or five years, and harvests can be multiple and possible almost every two years, up to 120 years for these species and indefinite for others. It has been successfully used to rehabilitate soil damaged by brick-making in India and abandoned mine sites in Malaysia (Ben-Zhi et al., 2005). Bamboo is generally used in soil stabilization, windbreaks; bamboo can be captured up to 17 metric tons of carbon per year. Hectare per year, that is, more efficiently, all bamboo shoots are edible, building and construction (Kenneth). Most bamboo houses are related to the needs of rural communities in developing countries. Different cultures have found in this material the economic system of a building, offering shelters that are light and easily replaceable. In their natural state, the solid stems halved stems or longitudinally divided strips bamboo are also used in almost all parts of the construction of a building, with the exception of the fireplace and chimney. The use of bamboo for the foundation is rather limited. This is mainly due to the fact that woods, in contact with moist soil, they can deteriorate and decompose very quickly if they are not treated with much more preservatives that have been very effective.(Patel, Parmar, \& Dave), The multiple purposes and uses given to bamboo have many different advantages, from support for construction, simple housing, bamboo furniture, to a musical instrument such as; flutes, dizi, xiao, shakuhachi, paper and clothes. A study published in India indicated that bamboo shoots are also consumed in many Asian countries. Therefore, the health benefits of bamboo shoots include healthy weight loss, balanced cholesterol, and so on. Bamboo can provide a solution to a very serious problem such as deforestation

\subsection{Consumers and Businessmen Perceptions}

Nowadays, the consumer buys the product according to his needs and his preferences. Perceived effectiveness of the consumer (PEC) has been defined as a belief specifically demonstrates that an individual's efforts can make a substantial difference from the solution to a given problem. The PEC is normally linked to the concept of perceived behavioral control, which has been studied by theoreticians in the areas of acquired helplessness (Rgn \& Rgn, 2002; Rothbaum, Weisz, \& Snyder, 1982). The actions or intentions of the subjects are influenced by the extent to which they think that the occurrence or aversion of an event may be affected by their actions (Noone, Wirtz, \& Kimes, 2012; Thompson, 1981). Although the CPE has been associated with more generalized feelings of control, it has been shown that the degree of behavioral control of behavior by a person is limited, in a unique way (Henion \& Wilson, 1976; Noone et al., 2012) (Ajzen, 2002). The new applications of the bamboo can be seen as the need of consumers allowing businessmen to implement or even improve the market to determine the most effective ways of converting the punctual customer into a regular consumer before to 2008. Consequently, businessmen believe that they defend free enterprise when they declare that their enterprise is not limited to promoting a desirable social end; this enterprise has a social conscience and takes seriously its responsibilities in terms of productive employment. Producers also need to know what to do with market demand. Today bamboo production is widely used with its various benefice applications. In this respect, training and capacity building are very important. So the countries even have to learn about the priorities of the country-based savers before even launching into production, having the bamboo applications that will be profitable or still feasible in the country. The businessmen have more interest in invest in the production of bamboo and attract other investors to take part not only for the profitability but also for the development of the national and international market. Accordingly, the following hypothesis is suggested:

Hypotheses $\left(H_{1)}\right.$ : The consumer's value within the importance of bamboo applications highlighting more than businessmen.

\section{Hypotheses $\left(\mathrm{H}_{2}\right)$ : Businessmen value within the perceived benefits of bamboo highlighting more than consumers}

\subsection{The Relationships between the Importance of Bamboo and the Perceived Benefits}

The relationship between the applications of the bamboo and the perceived benefits is related to different applications that are beneficial for the environment especially, and by implementing all its applications, they 
automatically linked to the environment. Bamboo grows very fast and establishes rapidly (Aiyeloja, Oladele, \& Furo, 2013) It grows both in the forest and plantation; In plantations where the selective annual harvest of mature culms occurs, bamboo can place on sequestration of carbon, especially if transformation and durability of carbon harvested in sustainable products (Akwade \& Akinlabi, 2016). Bamboos lock in more carbon when intensively managed. Therefore, the development of bamboo plantations is one of the main ways to reduce environmental impacts and climate change. According to the Environmental Bamboo Foundation (Ogunwusi \& Jolaoso, 2012) the growth uses of bamboo can provide more oxygen than a tree equivalent. The implications of these aspects are favorable for the reduction of atmospheric carbon dioxide. Using bamboo, which has the fastest growing canopy, bamboo can release about 35\% more oxygen than tree equivalents and can sequester up to 12 tons of carbon dioxide annually. Uses of crop materials refer to the carbon potential of sequestration in forest ecosystems. Bamboo is currently used for new applications and new needs have been developed almost everywhere. The fast growing-bamboo is very favorable for the environment by taking into account natural areas; therefore, it can grow up to 1 meter in 24 hours (Alfonso, 1987; Atanda, 2015). The production of the bamboo can be established from scratch in 10 years and individual stubble. The bamboo can be harvested every 3 to 6 years (depending on the species). The Advantages of bamboo plantings include lower levels of exposure to external hazards, such as fire, and flexibility to increase management and harvesting practices faster and comparatively with climate change (Lobovikov, Schoene, \& Yping, 2012). Investing in bamboo harvesting produces a quick source of income and an important safety record for bamboo producers. In addition, the bamboo planted on marginal lands can be considered as a major advantage, as well as steep slopes, degraded lands and thus leaving better land for more demanding crops (Fischer, Lindner, Abs, \& Lasch, 2002). As a result, bamboo can be planted in almost all degraded areas, especially in the eastern part of the country where erosion ravines and groundwater ravages and in soils damaged by overgrazing and poor techniques agricultural (Ogunwusi \& Jolaoso, 2012) (Pandey \& Shyamasundar, 2008). Today, bamboo applications are used in almost every day aspect by referring to the current society based on the protection of the environment. The bamboo can evince undoubtedly consistent with the sustainable development of green materials. The industrial production of bamboo products has a substitution impact on the applications of bamboo products. Different methods may be used to evaluate attributes performance of benefit of bamboo and to identify their importance of application bamboo. Attributes' performance level may be identified asking consumers and businessmen about their satisfaction with each attribute. As discussed above, we propose the following hypothesis:

Hypotheses $\left(H_{3-1}\right)$ : There is a positive correlation between the importance of the bamboo application and the perceived of bamboo benefits from consumers

Hypotheses $\left(H_{3-2}\right)$ : There is a positive correlation between the importance of the bamboo application and the perceived of bamboo benefits from businessmen.

2.6 Development of Importance Performance Analysis model for the Importance Application and the Perceived Benefit of Bamboo

Importance-Performance Analysis (IPA) (Deng, 2007; Martilla \& James, 1977) is a simple and useful technique that can help managers to determine which attributes need improvement to recognize overall customer satisfaction. This study supported the adoption of the importance-performance analysis (API) as an alternative framework to determine the importance of bamboo applications and the benefits of bamboo.

The study highlighted the function of two components: the importance of bamboo application or service to a consumer, businessmen and the performance of advantages of benefits within businessman in providing that service or product. In this way, the importance-performance analysis (IPA) examines not only the performance of an item, but also the importance of that item as a determining factor in satisfaction to the respondent (Pires Ferreira \& Odete Fernandes, 2015). So the vertical line in the IPA is the importance of the application, and the horizontal line is the performance due to the fact that it's replaced by the benefit for the investment. In this context, the first quadrant is the high importance and the high benefit that explained the application of bamboo; it can provide portability, based on the responses of the Respondents - the second quadrant is the high importance application which is not profitable but helpful - the third quadrant is the application with low importance and benefit explained by the conservative of application - the fourth quadrant is the application that doesn't have higher importance but benefits that means, it may be acceptable by the population. The combined consumers ratings for those two components then provide an overall view of satisfaction with clear directives for the management and where to focus agency resources, because it facilitates the interpretation of data and increases usefulness in making strategic decisions (Moitra). 


\begin{tabular}{|c|c|c|c|c|c|c|c|c|c|}
\hline \multirow{12}{*}{ Importance } & 10 & \multicolumn{3}{|l|}{ Quadrant II } & \multicolumn{5}{|c|}{ Quadrant I } \\
\hline & 9 & \multicolumn{3}{|l|}{ High Importance } & \multicolumn{5}{|c|}{ High Importance } \\
\hline & 8 & \multicolumn{3}{|l|}{ Low Benefit } & \multicolumn{5}{|c|}{ High Benefit } \\
\hline & 7 & & & & \multirow{2}{*}{\multicolumn{5}{|c|}{ (Profitable) }} \\
\hline & 6 & \multicolumn{3}{|l|}{ (Helpful ) } & & & & & \\
\hline & & & & & & & & & \\
\hline & 5 & \multicolumn{3}{|l|}{ Quadrant III } & \multicolumn{5}{|c|}{ Quadrant IV } \\
\hline & 4 & \multicolumn{3}{|l|}{ Low Importance } & \multicolumn{5}{|c|}{ Low Importance } \\
\hline & 3 & \multicolumn{3}{|l|}{ Low Benefit } & \multicolumn{5}{|c|}{ High Benefit } \\
\hline & 2 & & & & & & & & \\
\hline & 1 & \multicolumn{3}{|l|}{ (Conservative) } & \multicolumn{5}{|c|}{ (Acceptable) } \\
\hline & 0 & 3 & 4 & 5 & 6 & 7 & 8 & 9 & 10 \\
\hline & & \multicolumn{8}{|c|}{ Performance (Benefit) } \\
\hline
\end{tabular}

Figure 2. Strategy matrix of the study

\section{Methodology}

\subsection{Sample and Data Collection}

A simple is a set of selected individuals in a population and is usually intended to represent the population in a research study according to (Gravetter \& Forzano). Therefore, this study uses a sample whose respondents are under 30 years of age and has a minimum education level that resided in Haiti. In this study used two set questionnaires containing objective questions related to the important application and the benefits of bamboo as a function of consumer and businessmen to response. The questionnaire is divided into four sections: section one referred to the respondents' experiences using bamboo (four questions), section two included 20 applications with multiple choices (from A to $\mathrm{T}$, with each letter representing an application, for example A represent: bamboo housing, B represent: bamboo raw materials, C: represent bamboo charcoal, and T: represent bamboo paint brushes) measured on a five-point scale 1 (very poor) to 5 (very good) based on the benefits the respondents had to choose from, section three is about the benefits, with three questions for each advantage; responses were measured on a five-point Likert scale $(1=$ strongly disagree, $5=$ strongly agree). Section 4 referred to the personal information such as gender, age education and occupation. The first test will examine the validity and reliability of the questionnaire by testing it with 378 consumers and 91 businessmen with in-depth knowledge of the use of bamboo and its benefits. The comments and suggestions of these respondents were used to improve the questionnaire in terms of simplicity and ease of understanding. Responses were collected during face-to-face interviews with consumers and businessmen from June to August. A face-to-face survey was chosen as an instrument because it relies on personal interaction and can be controlled (Szolnoki \& Hoffmann, 2013), and they reduce the non-response rate (Hair Jr, Anderson, Tatham, \& Wiliam). According to the descriptive statistical results presented in Table 1, the majority of respondents were women (50.01\%), aged 31 to 40 (56.05\%), high school (45.06\%), public sector employees (26\%). 
Table 1. Demographic Characteristics of the Respondents $(n=469)$

\begin{tabular}{llll}
\hline Variables & Valid & Frequency & Percent \\
\hline \multirow{2}{*}{ Gender } & Male & 234 & 49.99 \\
& Female & 235 & 50.01 \\
Age & Below-30 & 70 & 14.99 \\
& 41-40 & 265 & 56.05 \\
Education & Above-51 & 123 & 26.02 \\
& Below-high school & 79 & 2.03 \\
& High school & 214 & 16.08 \\
& Bachelor's degree & 137 & 45.06 \\
& High education & 39 & 29.02 \\
& Unemployed & 108 & 8.03 \\
& Private Employee & 92 & 23.00 \\
& Public employee & 124 & 19.06 \\
& Business & 28 & 26.04 \\
& Manual & 68 & 6.00 \\
& Others & 49 & 14.05 \\
& & & 10.04 \\
\hline
\end{tabular}

\subsection{Measures}

Measurement variables considered five items describing the importance of bamboo and five items for the perceived benefits in this study. A total of ten variables were used. From the importance application we have: profitability, feasibility, acceptability, available, success; and from the perceived benefit we have: economic, social, environment, technology, security. All items are five-point Likert-types scales ranging from 1 (strongly disagree) to 5 (strongly agree). The two tables above list the measured items for the importance and the perceived benefit of the study.

Table 2. Measured items for the importance application

\begin{tabular}{lll}
\hline Variable & Measure & Source \\
\hline Profitability & This application of bamboo product can be profitable for Haiti. & \\
Feasibility & This application of bamboo product can be feasibility in Haiti. & \\
Acceptable & This application of bamboo product can be acceptable in Haiti. & (Choudhury, Sahu, \& Sharma, 2012; Lobovikov, 2003) \\
Available & This application of bamboo product can be available in Haiti. & \\
Success & This application of bamboo product can be successful in Haiti. & \\
\hline
\end{tabular}


Table 3. Measured items for the perceived benefits

\begin{tabular}{|c|c|c|}
\hline Variable & Measure & Source \\
\hline Economic & $\begin{array}{l}\text { I consider if Haiti plant bamboo, Haiti can export bamboo to another country. } \\
\text { If the government invests in bamboo, it can benefit the country and attract other } \\
\text { investments from oversea. } \\
\text { Overall bamboo plant grows rapidly and Haiti can be harvested in } 3-5 \text { years. }\end{array}$ & $\begin{array}{l}\text { (Lobovikov, Ball, Guardia, \& } \\
\text { Russo, 2007) }\end{array}$ \\
\hline Social & $\begin{array}{l}\text { I consider if the bamboo can be used as a supplementary source of energy in Haiti. } \\
\text { I consider if Haiti adopts the bamboo housing as an alternative, it can help the } \\
\text { country to definitely eradicate the tent phenomenon. } \\
\text { I consider if the bamboo is used for water filtration in Haiti, the low income } \\
\text { population can have a better access to drinking water. }\end{array}$ & Scurlock, Dayton et al. 2000 \\
\hline Environment & $\begin{array}{l}\text { I consider the fast grow of bamboo plantation can be benefits to Haiti again } \\
\text { deforestation. } \\
\text { I consider bamboo plant can grow without pesticides or chemical fertilizers and } \\
\text { requires no irrigation for Haiti. } \\
\text { I consider bamboo can be used as a mean to reclaim degraded land, conserve soil, } \\
\text { improve environment, } \\
\text { Carry out drought proofing for Haiti }\end{array}$ & $\begin{array}{l}\text { (Kusters, Achdiawan, Belcher, \& } \\
\text { Ruiz Pérez, 2006) }\end{array}$ \\
\hline Technology & $\begin{array}{l}\text { I consider that bamboo's production can develop new technology to innovate } \\
\text { industries in Haiti. } \\
\text { I consider that Haiti can develop the pharmaceutical industry through its bamboo } \\
\text { production. } \\
\text { I consider that Haiti can develop the technology of ethanol through oligosaccharides } \\
\text { hydrolysis of the bamboo. }\end{array}$ & (Mudjanarko \& Mayestino, 2017) \\
\hline Security & $\begin{array}{l}\text { I consider if Haiti embrace bamboo plantation, it reduce erosion, deforestation, and } \\
\text { there for increase reforestation. } \\
\text { I consider if we built more bamboo houses, we can have fewer deaths in natural } \\
\text { catastrophes especially earthquakes in Haiti. } \\
\text { I consider with bamboo plant for water filtration that we can reduce the cholera rate } \\
\text { in Haiti and others. }\end{array}$ & (Ben-Zhi et al., 2005) \\
\hline
\end{tabular}

\subsection{Tools for Analysis}

The analysis data for this study were constructed using the statistical software for the social sciences (SPSS 22.0) and the moment structure analysis software (AMOS 22.0). SPSS software was used for descriptive analysis depending on the demographic characteristics of the sample. The Cronbach alpha coefficient was used to test the reliability of the measurement elements. The ANOVA test will be used for the importance performance analysis to position which application and the perceived benefit will be more important for the country base on the strategically matrix form consumers and businessmen views.

\section{Results and Discussion}

\subsection{Testing of Reliability and Validity of the Measurement Model}

The construct reliability and validity was testing using ten attributes, fives for the importance of bamboo profitability, feasibility, available, acceptable and success, for the perceived benefits; economic, social, environmental, technology and security. To study the internal consistency of the indicators of each construction studied, the most common method consisted in identifying the alpha coefficient of a given construction. (Henseler, Ringle, \& Sinkovics, 2009). The table 4 showed, the Cronbach's $\alpha$ coefficient ranged from 0.819 to 0.926 for consumers and 0.928 to 0.959. (Nunnally \& Bernstein, 1994; Orme \& Combs-Orme, 2009) suggested the level of Cronbach's $\alpha$ beyond 0.70 . In fact, the values obtained from the analysis suggested that all constructs were internally consistent and reliable. 
Table 4. The reliability among importance application and perceived benefits

\begin{tabular}{|c|c|c|c|c|c|c|c|}
\hline \multirow[b]{2}{*}{ Variable } & \multicolumn{3}{|c|}{ Importance Applications } & \multicolumn{4}{|c|}{ Perceived Benefits } \\
\hline & Items & $\begin{array}{l}\text { M } \\
\text { (Std) }\end{array}$ & Cronbach's $\alpha$ & Variable & Items & $\begin{array}{l}\text { M } \\
\text { (Std) }\end{array}$ & Cronbach's $\alpha$ \\
\hline Pro & 4 & $\begin{array}{l}4.636 \\
(0.464)\end{array}$ & 0.926 & Eco & 3 & $\begin{array}{l}4.650 \\
(0.488)\end{array}$ & 0.958 \\
\hline Fea & 4 & $\begin{array}{l}4.643 \\
(0.464)\end{array}$ & 0.920 & Soc & 3 & $\begin{array}{l}4.730 \\
(0.432)\end{array}$ & 0.953 \\
\hline Acc & 4 & $\begin{array}{l}4.647 \\
(0.458)\end{array}$ & 0.919 & Env & 3 & $\begin{array}{l}4.674 \\
(0.468)\end{array}$ & 0.956 \\
\hline Ava & 4 & $\begin{array}{l}4.647 \\
(0.455)\end{array}$ & 0.915 & Tech & 3 & $\begin{array}{l}4.595 \\
(0.544)\end{array}$ & 0.928 \\
\hline Suc & 4 & $\begin{array}{l}4.750 \\
(0.360)\end{array}$ & 0.819 & Sec & 3 & $\begin{array}{l}4.654 \\
(0.468)\end{array}$ & 0.958 \\
\hline
\end{tabular}

This paper used 20 applications among the different application of bamboo to present to the respondent after the elaboration of the benefit for the country; and the responses has filled in the five criteria attributes for the importance of application with 5 point scale 1 (very poor) to 5 (very good) Therefore the results in table 3 showed 2 groups are formed based on their frequencies, the first groups are the high importance group represented with 5 applications Items represented by bamboo housing with a Freq. of (247), following by $\mathrm{F}$ (bamboo flooring) (162) Freq. with an overall percentage of $48.90 \%$, the mean (4.989), and the Std (0.217). The second is the low importance group represented by 15 applications items which G represent bamboo panels, I bamboo food and lastly $\mathrm{T}$ (bamboo paint brushes) with an overall percentage $51.1 \%$, the mean $(4.155)$, and the Std (0.052).

Table 5. Frequencies bamboo applications for consumers

\begin{tabular}{|c|c|c|c|c|c|c|}
\hline \multirow{5}{*}{ High Importance } & Items & Description Items & Freq. & \multirow[t]{3}{*}{$\%$} & \multirow[t]{3}{*}{ M } & \multirow[t]{3}{*}{ Std } \\
\hline & A & Bamboo Housing & 247 & & & \\
\hline & $\mathrm{F}$ & Bamboo Flooring & 162 & & & \\
\hline & $\mathrm{C}$ & Bamboo Charcoal & 123 & \multirow[t]{10}{*}{48.90} & \multirow[t]{10}{*}{4.989} & \multirow[t]{10}{*}{0.217} \\
\hline & $\mathrm{L}$ & Bamboo Fuel & 105 & & & \\
\hline & M & Bamboo Fabrics & 105 & & & \\
\hline & G & Bamboo Panels & 98 & & & \\
\hline & I & Bamboo Food & 89 & & & \\
\hline & $\mathrm{E}$ & Bamboo Paper & 85 & & & \\
\hline & $\mathrm{D}$ & Bamboo Pub & 72 & & & \\
\hline & $\mathrm{N}$ & Bamboo Clothing & 67 & & & \\
\hline & $\mathrm{J}$ & Bamboo Bed sheets & 54 & & & \\
\hline & $\mathrm{S}$ & Bamboo Bed sheets & 51 & & & \\
\hline \multirow[t]{8}{*}{ Low Importance } & $\mathrm{K}$ & Bamboo Instruments & 49 & \multirow[t]{8}{*}{51.1} & \multirow[t]{8}{*}{4.155} & \multirow[t]{8}{*}{0.052} \\
\hline & B & Bamboo Raw Materials & 47 & & & \\
\hline & $\mathrm{P}$ & Bamboo Matting & 33 & & & \\
\hline & $\mathrm{R}$ & Bamboo Blinds & 30 & & & \\
\hline & $\mathrm{H}$ & Bamboo Crafts & 29 & & & \\
\hline & $\mathrm{O}$ & Bamboo Garden & 25 & & & \\
\hline & Q & Bamboo Cutting boards & 22 & & & \\
\hline & $\mathrm{T}$ & Bamboo Paint brushes & 19 & & & \\
\hline
\end{tabular}




\subsection{Comparison between the Consumers and Businessmen Views}

According to (Nowlis \& Simonson, 1996, 2005) consumers often value products in relation to the price they pay; in that perspective, the perceived value of the price is a determining factor in the choice of a product. As part of this study, the respondents are considered as a beneficiary of the different beneficial benefits of the bamboo plant for the country both on the environmental plant, economy, social, technologies and security in direct relation with the population. Therefore the businessman must link the investment activity to its fundamental causes rather than their shadow to finally give that preference that should be supported on a broader basis than elegance and aesthetics? If the best explanation of investment behavior also provides the best forecasting technique, the forecast and explanation should not be separate activities and no dissemination of the resources of the profession is required. In fact, Table 4 shows the comparison between the points of view of consumers and businessmen, the finding showed for the Acc $t=30.761 * * * p=0.000$, Ava $t=32.223 * * * p=0.000$, Suc $t=40.048 * * * p=0.000$ of the importance of bamboo applications, the consumers views were higher than businessmen view as explained the consumers concerned the importance of bamboo base on their knowledge about bamboo in particular, has become a popular non- timber forest product as it used by rural communities in the developing world for food, building materials, cash income furniture, and crafts (Wang, Yue, Tang, \& Sun, 2012) that indicated $\mathrm{H}_{1}$ was supported. The businessmen views were higher than the consumer's views for Pro $t=-2.922 * * p=(0.004)$ and Fea $t=-1.861, p=(0.064)$ and the businessmen be concerned about the benefit of bamboo products based on the thus industry for development of market products in the country; however bamboo as with economy potential and significant development is globally accepted. In case the result shows no expectation gap between the consumers and businessmen, because there are no differences. It plays a major role in the development of many countries with more than 2.5 billion people in the world dependent on survival and livelihoods. Friar and (Friar \& Kochert, 1991; Sun, Xia, \& Stapleton, 2006). The other side, for the perceive benefit the perception of consumers and businessmen is almost the same that means no significant difference for the expectation gap, both of them concerned the benefit about of bamboo.

Table 6. Comparison of Consumers and Businessmen Views

\begin{tabular}{|c|c|c|c|c|c|c|c|}
\hline \multirow{4}{*}{ Var. } & \multicolumn{4}{|c|}{ Importance Bamboo } & \multicolumn{3}{|c|}{ Perceive Benefits } \\
\hline & Consumers & Businessmen & & & Consumers & Businessmen & \\
\hline & $\mathrm{M}$ & $\mathrm{M}$ & $t$-value & & $\mathrm{M}$ & $\mathrm{M}$ & t-value \\
\hline & $(\mathrm{Std})$ & (Std) & p-value & vallautes & (Std) & (Std) & p-value \\
\hline \multirow{2}{*}{ Pro } & 4.636 & 4.764 & $-2.922 * *$ & \multirow{2}{*}{ Eco } & 4.650 & 4.722 & -1.267 \\
\hline & $(0.464)$ & $(0.348)$ & $(0.004)$ & & 0.488 & 0.469 & $(0.196)$ \\
\hline \multirow{2}{*}{ Fea } & 4.643 & 4.723 & -1.861 & \multirow{2}{*}{ Soc } & 4.730 & 4.751 & -0.425 \\
\hline & $(0.464)$ & $(0.339)$ & $(0.064)$ & & 0.432 & 0.405 & $(0.659)$ \\
\hline \multirow{2}{*}{ Acc } & 4.647 & 2.593 & $30.761 * * *$ & \multirow{2}{*}{ Env } & 4.674 & 4.736 & -1.163 \\
\hline & 0.458 & $(0.596)$ & 0.000 & & 0.468 & 0.429 & $(0.222)$ \\
\hline \multirow{2}{*}{ Ava } & 4.647 & 2.429 & $32.223 * * *$ & \multirow{2}{*}{ Tech } & 4.595 & 4.619 & -0.379 \\
\hline & 0.455 & 0.617 & $(0.000)$ & & 0.544 & 0.513 & $(0.695)$ \\
\hline \multirow{2}{*}{ Suc } & 4.750 & 2.725 & $40.048 * * *$ & \multirow{2}{*}{ Sec } & 4.654 & 4.714 & -1.112 \\
\hline & 0.360 & 0.449 & $(0.000)$ & & 0.468 & 0.435 & $(0.247)$ \\
\hline Overall & 4.665 & 3.447 & $27.721 * * *$ & Overall & 4.661 & 4.708 & -0.995 \\
\hline Import & $(0.430)$ & $(0.365)$ & $(0.00)$ & Benefits & $(0.437)$ & 0.405 & $(0.321)$ \\
\hline
\end{tabular}

Note: $* p<0.05, * * p<0.01, * * * p<0.001$

\subsection{Redundancy Analysis of Consumer's Views and Businessmen Views}

According to analysis (Van Den Wollenberg, 1977), redundancy index (RDA) is useful for demonstrating the relationships between two sets of variables and shows advantages in revealing the strength and direction of the correlation between them. The redundancy index provides a summary measure of the ability of a set of variables to explain variation in the other set of variables. In the present case, the redundancy helps identifying how much the importance of application can explain the perceived benefits for consumer's views and businessmen views. Table 7 displays form the consumers the importance application can explain in 2 factors by a total of $97.43 \%$ and from the perceived benefit by $84.47 \%$. Further results show the redundancy index of the important application is higher than the benefit that means the importance of application can explain by the perceived benefit for $68.92 \%$ and the benefits can explain by the benefits for $58.08 \%$ this finding means the consumer care 
more about the benefits of the application. Thus $\mathrm{H}_{1}$ and $\mathrm{H}_{3-1}$ were supported by the study.

Table 7. Canonical correlation redundancy of consumers views

\begin{tabular}{|c|c|c|c|c|c|}
\hline \multicolumn{4}{|c|}{ C_Importance } & \multicolumn{2}{|r|}{ C_Benefit } \\
\hline & $\mathrm{X}_{1}{ }^{*}$ & $\mathrm{X}_{2}{ }^{*}$ & & $\mathrm{Y}_{1}^{*}$ & $\mathrm{Y}_{2}^{*}$ \\
\hline Profitability & 0.99 & -0.13 & Economy & 0.93 & 0.03 \\
\hline Feasibility & 0.98 & -0.02 & Social & 0.83 & 0.29 \\
\hline Acceptable & 0.98 & -0.09 & Environment & 0.86 & -0.15 \\
\hline Available & 0.99 & -0.03 & Technology & 0.89 & -0.37 \\
\hline Success & 0.93 & 0.30 & Security & 0.94 & 0.00 \\
\hline Variation Extracted & $95.15 \%$ & $2.28 \%$ & $\begin{array}{l}\text { Variation } \\
\text { Extracted }\end{array}$ & $79.55 \%$ & $4.92 \%$ \\
\hline Total & $97.43 \%$ & & Total & $84.47 \%$ & \\
\hline RI & $68.58 \%$ & $0.34 \%$ & RI & $57.33 \%$ & $0.75 \%$ \\
\hline Total RI & $68.92 \%$ & & Total RI & $58.08 \%$ & \\
\hline$\lambda_{1}=0.721 \quad \rho_{1}=0.84$ & & & $\lambda_{2}=0.152$ & $89^{* * *}$ & \\
\hline
\end{tabular}

Note: ${ }^{*}<<0.05,{ }^{* *} p<0.01,{ }^{* * *} p<0.001$.

As explained by (Hair, 2010), the redundancy index was proposed as a measure of shared variance to overcome bias, misinterpretation and uncertainly that might exist with the use of squared canonical correlations since they also provide an estimate of the shared variance between canonical variance. The analysis yielded on Table 6 showed two statistically significant functions with squared canonical correlations of 0.722 and 0.525 with a p-value level (0.001) for each successive significant function. Collectively, the model across all function was statistically significant using the Wilks's $\lambda=0.521$ and 0.276 . Thus, for the sets of two pairs factors canonical functions the importance application can explain itself by $83.73 \%$ for the businessmen and for the perceived benefit by $84.07 \%$ may that means the businessmen cannot be concerned only for the benefits because most the application is important of the market most the businessmen may more money. In fact the businessmen need to know the perception of the population needs for application before the benefit. The redundancy index of both is almost the same, the perceived benefit can explain the application by $40.46 \%$ and the importance of application can only explain the perceived benefit by $39.49 \%$. Based on the results finding $\mathrm{H}_{2}$ and $\mathrm{H}_{3-2}$ was supported.

Table 8. Canonical correlation redundancy of businessmen views

\begin{tabular}{|c|c|c|c|c|c|}
\hline \multicolumn{4}{|c|}{ B_Importance } & \multicolumn{2}{|r|}{ B_Benefit } \\
\hline & $\mathrm{X}_{1}{ }^{*}$ & $\mathrm{X}_{2}{ }^{*}$ & & $\mathrm{Y}_{1}{ }^{*}$ & $\mathrm{Y}_{2}^{*}$ \\
\hline Profitability & 0.83 & 0.23 & Economy & 0.89 & 0.26 \\
\hline Feasibility & 0.63 & 0.73 & Social & 0.92 & 0.24 \\
\hline Acceptable & 0.93 & 0.31 & Environment & 0.64 & 0.55 \\
\hline Available & 0.85 & 0.09 & Technology & 0.80 & 0.50 \\
\hline Success & 0.85 & 0.33 & Security & 0.91 & 0.08 \\
\hline Variation Extracted & $67.89 \%$ & $15.84 \%$ & $\begin{array}{l}\text { Variation } \\
\text { Extracted }\end{array}$ & $70.26 \%$ & $13.81 \%$ \\
\hline Total & $83.73 \%$ & & Total & $84.07 \%$ & \\
\hline RI & $35.41 \%$ & $4.38 \%$ & RI & $36.64 \%$ & $3.82 \%$ \\
\hline Total RI & $39.49 \%$ & & Total RI & $40.46 \%$ & \\
\hline$\lambda_{1}=0.521 \quad \rho_{1}=0.722^{* * *}$ & & & $\lambda_{2}=0.276 \quad \rho_{2}$ & & \\
\hline
\end{tabular}

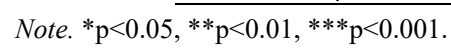

\subsection{The Position of the Importance Application and the Perceived Benefits}

\section{First Part from consumers}

This study used the importance performance analysis (IPA) with the ANOVA test to evaluate which application is more important for the consumer's knowledge for the population based on the needs of consumers. In the 
following figures where, the influenced perceptions regarding standards-based language learning by the respondents from a number of advantage points and the application $G$ bamboo panels (wall room) chosen of respondents indicated that this application is more important of the IPA and had a positive position on both side after standardizing; these results explained with this application that the consumers or the population have multiple purposes like (table, chair, floor. etc.), including other application, A (bamboo housing) and $\mathrm{F}$ (bamboo flooring).

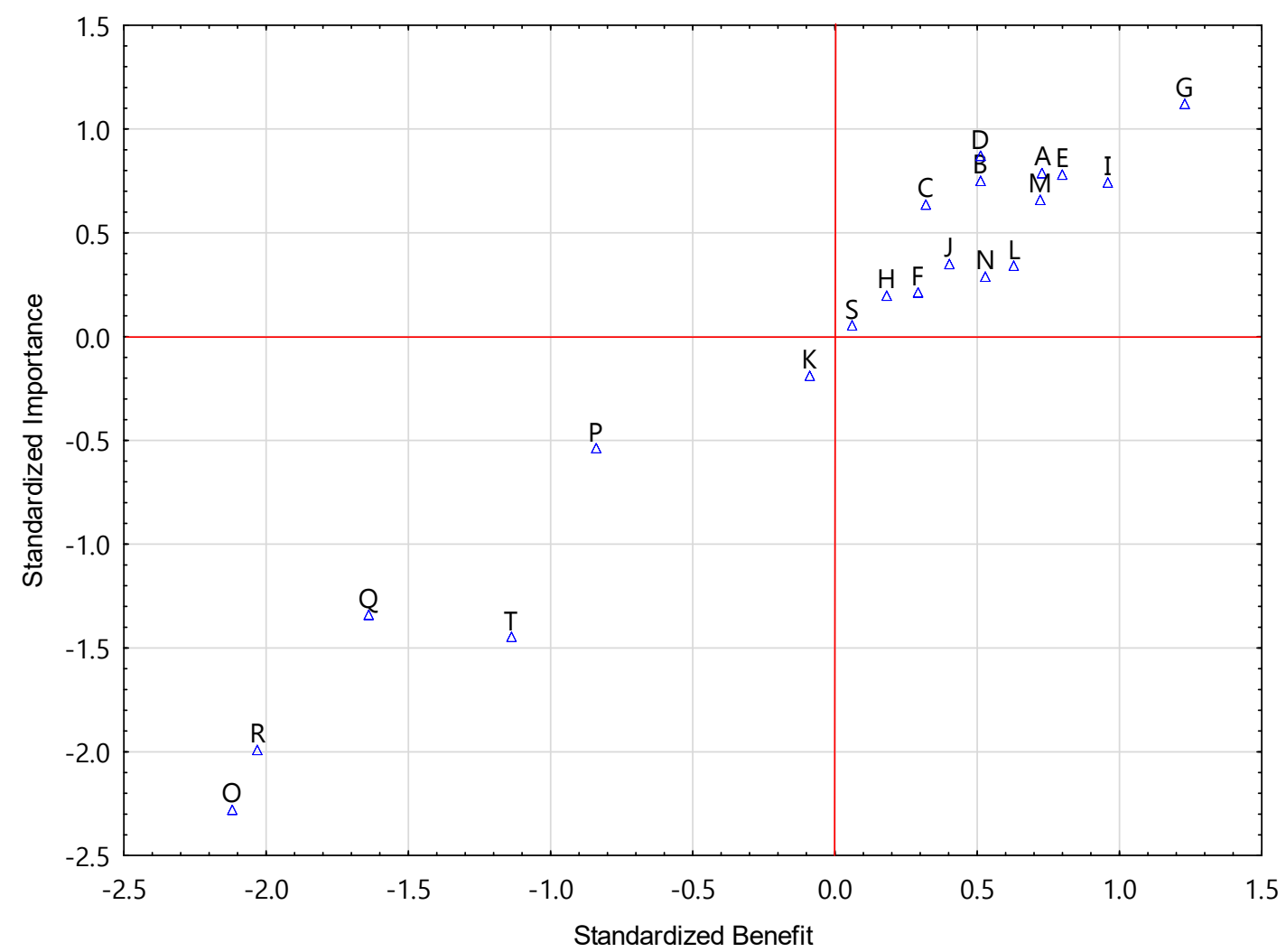

Figure 3. Scatter plot of Benefits against Importance

The application G (Bamboo panels) didn't have the most frequencies regarded the results of frequencies (table 5) however the average score was higher than the other applications from the importance application and the perceived benefits. Other studies have shown that many of the most industries are based on bamboo wood replacement already taking shape in China, to replace wood with bamboo; the main approach is to mass produce bamboo panels as a replacement for various woods. On the other hand, the main bamboo woven products, laminated bamboo plywood, bamboo veneer panels, overlay decorative panels, bamboo flooring, bamboo composite panels; bamboo panels (Yang \& Hui, 2010).

\section{Second part from businessmen}

The following comments reflect the industry based on the occupation from the businessmen to which the IPA influenced instruction and future assessment plans of importance bamboo applications and the perceived benefits. The scatter plot of figure 3 showed positive position of the fabrication, fallowing by the food \& service, and the furniture production based on the occupation of businessmen. The horizontal line showed the level of the importance and the vertical line showed the level of the benefits performance. As a result, the development of competitive products on the market is possible. 


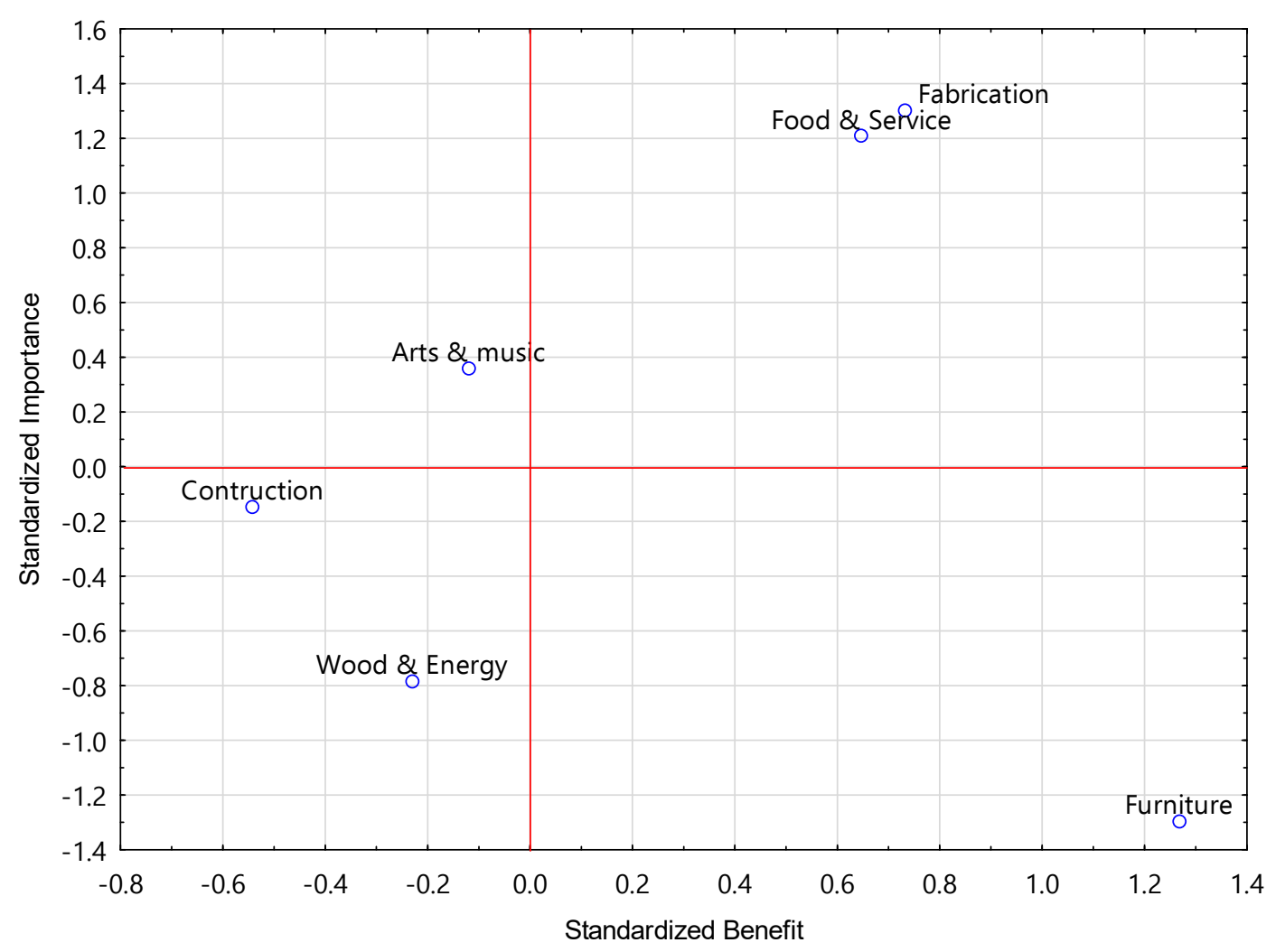

Figure 4. Scatter plot of Benefits against Importance

The furniture is higher for the benefit but not for the important part because bamboo uses for furniture are durable. The benefit of the furniture described as the durability, strength of the bamboo product (Wahab \& Samsi, 2004). Therefore, consumers should be willing to take advantage of the benefits of bamboo purchased in different cost-effective applications for the country, as several options can be eliminated either by selective collection, by local government or by citizen groups, by the establishment of centralization. In both cases, businessmen could benefit from bamboo production based on social, environmental and other benefits (Vogtländer, Van der Lugt, \& Brezet, 2010). Subsequent studies have described the economic importance and benefits of bamboo applications because rapid growth, renewal capacity, strength, and a large number of applications that result from it provide a wide range of goods and services to human (Lobovikov et al., 2007), where it is an integral part of people's lives, and even in the history of food. The number of increasing uses is also known today, because, according to the evolution of industrial techniques, it has been possible to manufacture bamboo production in new forms (Mera \& Xu, 2014). Bamboo grows much faster than timber tree species and requires less intensive management and expertise. It may be harvested annually without depletion and deterioration of the soil; it can grow on marginal land not suitable for agriculture and regenerates easily. It is easier to harvest and transport than timber tree species; since, with bamboo such activities doesn't require specialized equipment or vehicles; it splits easily for weaving and is thus easy to handle also for women (Xu, Zhou, Du, \& Partida, 2012)

\section{Conclusion}

Promoting bamboo fibers will result in the cultivation and promotion of fiber types that have the potential to fulfill material needs with less resource consumption and less production of various fiber types. Diversity in raw materials provides a way to promote sustainability in textile fashion as well (Yoo, Divita, \& Kim, 2013). Increasing awareness and building knowledge of bamboo textiles will also allow manufacturers to adopt new materials. One way to motivate companies to use sustainable fibers in their products is to emphasize their benefits and profits in the long term, along with environmental issues (Batalha et al., 2011). This study examined the importance of applications and the perceived benefits of bamboo- a comparison between consumers and businessmen. The aim was to bring together the different applications of bamboo and the benefit, second: to compare the consumers views and businessmen views, to third: find the correlation between the importance of 
bamboo applications and the perceived benefits, and finally apply the importance performance analysis (IPA) model to position the expected application and benefit of bamboo in Haiti. The results of this research indicated two groups were formed that bamboo housing and bamboo flooring showed the highest importance of bamboo applications group. In addition, the respondents have chosen these applications because most of the relief of the disadvantaged areas on the tents since the natural disaster (earthquakes) that destroyed the country. And by listing the various problems that the country is facing today, we can consider the beneficial application of bamboo as a form of development for the country on many different points. Based on these results, the consumer's views were higher than businessmen for the importance of bamboo, we can consider the wants and the needs of consumers for the country, and also the businessmen view was higher than consumers for the perceived benefits, based on the industry of bamboo-like - Fabrication and wood-industry. Therefore, the importance of applications was strongly correlated to the perceived benefits of both all of them. Bamboo was one of the building materials currently used by humanity today. The bamboo stalk is able to produce after processing a quantity of product ranging from domestic applications to industrial applications. Examples of bamboo products include skewers, chopsticks, crafts, toys, furniture, flooring, pulp and paper, boats, charcoal, musical instruments, and others. According to the answers of respondent knowledge about the bamboo application with like a products might be a new innovation and very beneficial economically, socially, environmentally, and technologically for the country. This research may consider if the population plants bamboo, it can export bamboo to other countries and if the government invests in bamboo, it can benefit for the country by attracting other investments from the overseas, referring to the overall bamboo plant growing. The bamboo may be used as an alternative source of energy; therefore the rural population may have better access to electricity. Moreover, if the population adopts the bamboo housing as an alternative, it can help the country to definitely eradicate the tent phenomenon. In fact, the bamboo can also be used for water filtration; therefore, the low-income population can have better access to drinking water. The fast-growing of bamboo plantations might be the benefit to Haiti against the deforestation.

Acknowledgments: We would like to thank the survey respondents for taking their time to answer the questionnaire and the reviewers of this paper for their valuable comments.

Author Contributions: Daphney Francois and Shu-Yi Liaw were responsible for the concept, research design, statistical analysis and writing the manuscript. Daphney Francois distributed the survey.

Conflicts of Interest: The authors declare no conflict of interest.

\section{References}

Aiyeloja, A., Oladele, A., \& Furo, S. (2013). Sustaining livelihood through sawn wood marketing in Port Harcourt, Nigeria. Int. J. Sci. Nature, 4(1), 84-89.

Ajzen, I. (2002). Perceived behavioral control, self-efficacy, locus of control, and the theory of planned behavior. Journal of Applied Social Psychology, 32(4), 665-683. https://doi.org/10.1111/j.1559-1816.2002.tb00236.x

Akwade, D., \& Akinlabi, E. T. (2016). Economic, social and environmental assessment of bamboo for infrastructure development. Edited by the International Conference on Infrastructure Development in Africa Copyright (C) 2016 ICIDA-2016

Alfonso, D. (1987). Let's plant bamboo. Weekly Agribusiness. Retrieved from http://www.akademiabaru.com/arfmts.html

Batalha, L. A. R., Colodette, J. L., Gomide, J. L., Barbosa, L. C., Maltha, C. R., \& Gomes, F. J. B. (2011). Dissolving pulp production from bamboo. BioResources, 7(1), 0640-0651.

Ben-Zhi, Z., Mao-Yi, F., Jin-Zhong, X., Xiao-Sheng, Y., \& Zheng-Cai, L. (2005). Ecological functions of bamboo forest: research and application. Journal of Forestry Research, 16(2), 143-147. https://doi.org/10.1007/BF02857909

Cerling, T. E. (1992). Development of grasslands and savannas in East Africa during the Neogene. $\begin{array}{llll}\text { Palaeogeography, } & \text { Palaeoclimatology, } & \text { Palaeoecology, } & 97(3),\end{array}$ https://doi.org/10.1016/0031-0182(92)90211-M

Fischer, A., Lindner, M., Abs, C., \& Lasch, P. (2002). Vegetation dynamics in central European forest ecosystems (near-natural as well as managed) after storm events. Folia Geobotanica, 37(1), 17-32 https://doi.org/10.1007/BF02803188.

Friar, E., \& Kochert, G. (1991). Bamboo germplasm screening with nuclear restriction fragment ength polymorphisms. Theoretical and Applied Genetics, 82(6), 697-703. https://doi.org/10.1007/BF00227313 
Gravetter, F., \& Forzano, L. (2012). Research methods for the behavioral sciences. Wadsworth, Cengage Learning. International Edition: ISBN-13, 978-971.

Hair Jr, J. F., Anderson, R. E., Tatham, R. L., \& Wiliam, C. Black, (1988). Mulivariate Data Analysis: New Jersey, Prentice Hall.

Hair, J. F. (2010). Black, WC, Babin, BJ, \& Anderson, RE (2010). Multivariate data analysis, 7.

Henion, K. E., \& Wilson, W. H. (1976). The ecologically concerned consumer and locus of ontrol. Ecological marketing, 131.

Henseler, J., Ringle, C. M., \& Sinkovics, R. R. (2009). The use of partial least squares path modeling in international marketing New challenges to international marketing (pp. 277-319): Emerald Group Publishing Limited.

Hunter, I. R. (2003). Bamboo resources, uses and trade: the future. Journal of Bamboo and Rattan, 2(4), 319-326.

Kenneth, H. L. (1972). Building Materials. http://dx.doi.org/10.4314/just.v32i3.4

Kusters, K., Achdiawan, R., Belcher, B., \& Ruiz Pérez, M. (2006). Balancing development and conservation? An assessment of livelihood and environmental outcomes of nontimber forest product trade in Asia, Africa, and Latin America. http://hdl.handle.net/10170/475

Lessard, G., \& Chouinard, A. (1980). Bamboo research in Asia: proceedings of a workshop held in Singapore, 28-30 May 1980: IDRC, Ottawa, ON, CA.

Liu, D., Song, J., Anderson, D. P., Chang, P. R., \& Hua, Y. (2012). Bamboo fiber and its reinforced composites: structure and properties. Cellulose, 19(5), 1449-1480. https://doi.org/10.1007/s10570-012-9741-1

Lobovikov, M., Ball, L., Guardia, M., \& Russo, L. (2007). World bamboo resources: a thematic study prepared in the framework of the global forest resources assessment 2005: Food \& Agriculture Org. books.google.com

Lobovikov, M., Schoene, D., \& Yping, L. (2012). Bamboo in climate change and rural livelihoods. Mitigation and Adaptation Strategies for Global Change, 17(3), 261-276. https://doi.org/10.1007/s11027-011-9324-8

Martilla, J. A., \& James, J. C. (1977). Importance-performance analysis. The journal of marketing, 77-79. https://doi.org/10.1177/002224297704100112

Mera, F. A. T., \& Xu, C. (2014). Plantation management and bamboo resource economics in China. Revista Ciencia Y Tecnología, 7(1), 1-12. https://doi.org/10.18779/cyt.v7i1.93

Moitra, M. R. Using Importance Performance Analysis in Evaluating Students Satisfaction in Higher Educational Institutes.

Mudjanarko, S. W., \& Mayestino, M. (2017). Engineering Technology Of Bamboo Material And Additive Foam Concrete As Mixed Material Testing On Paving Production. JURNAL LENTERA: Kajian Keagamaan, Keilmuan Dan Teknologi, 3(2).

New York State Department of Environmental Conservation. (2009). Guidelines for conducting bird and bat studies at commercial wind energy projects. Albany, NY Retrieved from http://www.dec.ny.gov/docs/wildlife_pdf/windguidelines.pdf.

Noone, B. M., Wirtz, J., \& Kimes, S. E. (2012). The effect of perceived control on consumer responses to service encounter pace: A revenue management perspective. Cornell Hospitality Quarterly, 53(4), $295-307$. https://doi.org/10.1177/1938965512460343

Nowlis, S. M., \& Simonson, I. (1996). The effect of new product features on brand choice. Journal of marketing research, 36-46. https://doi.org/10.1177/002224379603300104

Nowlis, S. M., \& Simonson, I. (2005). The introduction of new features and enhancements is one of the most common methods for differentiating products and services and increas-ing sales. For example, Minolta gained a significant competitive advantage when it was the first company to introduce cameras with an automatic focus system. A question that naturally arises is: What factors determine the. Consumer decision-making, 1(1), 332.

Nunnally, J. C., \& Bernstein, I. (1994). Psychometric Theory (McGraw-Hill Series in Psychology) (Vol. 3): McGraw-Hill New York. https://doi.org/10.1016/S0148-2963(99)00098-3 
Ogunwusi, A., \& Jolaoso, M. (2012). Advances in Arts, Social Sciences and Education Research.

Orme, J. G., \& Combs-Orme, T. (2009). Multiple regression with discrete dependent variables: Oxford University Press.

Pandey, C., \& Shyamasundar, K. (2008). Post harvest management and storage of bamboo culms. Paper presented at the Proceedings of the International Conference on Improvement of Bamboo productivity and marketing for sustainable livelihood. 15th-17th April.

Patel, N., Parmar, D., \& Dave, S. Utilization of Bamboo as a Substitute Building Material.

Pires Ferreira, H., \& Odete Fernandes, P. (2015). Identification of critical success factors that maximise customers' satisfaction: multivariate analysis. Tourism \& Management Studies, 11(1). https://doi.org/10.1016/j.procs.2015.08.634

Rgn, A. H., \& Rgn, H. E. W. (2002). Role of self-efficacy and behaviour change. International journal of nursing practice, $8(2), 106-115$.

Rothbaum, F., Weisz, J. R., \& Snyder, S. S. (1982). Changing the world and changing the self: A two-process model of perceived control. Journal of Personality and Social Psychology, 42(1), 5. http://dx.doi.org/10.1037/0022-3514.42.1.5

Sen, T., \& Reddy, H. J. (2011). Application of sisal, bamboo, coir and jute natural composites in structural upgradation. International Journal of Innovation, Management and Technology, 2(3), 186.

Shen-xue, J., Qi-sheng, Z., \& Shu-hai, J. (2002). On Structure, production, and market of bamboo-based panels in China. Journal of Forestry Research, 13(2), 151-156. https://doi.org/10.1007/BF02857243

Sulaiman, O., Hashim, R., Wahab, R., Ismail, Z., Samsi, H. W., \& Mohamed, A. (2006). Evaluation of shear strength of oil treated laminated bamboo. Bioresource Technology, 97(18), 2466-2469. https://doi.org/10.1016/j.biortech.2005.10.026

Sun, Y., Xia, N., \& Stapleton, C. M. (2006). Relationships between Bambusa species (Poaceae, Bambusoideae) revealed by random amplified polymorphic DNA. Biochemical systematics and ecology, 34(5), 417-423 https://doi.org/10.1016/j.bse.2005.10.015.

Szolnoki, G., \& Hoffmann, D. (2013). Online, face-to-face and telephone surveys-Comparing different sampling methods in wine consumer research. Wine Economics and Policy, 2(2), 57-66 https://doi.org/10.1016/j.wep.2013.10.001.

Thompson, P. (1981). Velocity after-effects: the effects of adaptation to moving stimuli on the perception of subsequently seen moving stimuli. Vision research, 21(3), 337-345.

Thwe, M. M., \& Liao, K. (2003). Durability of bamboo-glass fiber reinforced polymer matrix hybrid composites. Composites science and technology, 63(3-4), 375-387 https://doi.org/10.1016/S0266-3538(02)00225-7.

Van Den Wollenberg, A. L. (1977). Redundancy analysis an alternative for canonical correlation analysis. Psychometrika, 42(2), 207-219. https://doi.org/10.1007/BF02294050

Vogtländer, J., Van der Lugt, P., \& Brezet, H. (2010). The sustainability of bamboo products for local and Western European applications. LCAs and land-use. Journal of Cleaner Production, 18(13), 1260-1269. https://doi.org/10.1016/j.jclepro.2010.04.015

Wahab, R., \& Samsi, H. (2004). Strength and durability of bamboo treated through an oil-curingprocess. Journal of Biological Sciences (Pakistan).

Wang, J., Yue, Y.-D., Tang, F., \& Sun, J. (2012). TLC screening for antioxidant activity of extracts from fifteen bamboo species and identification of antioxidant flavone glycosides from leaves of Bambusa. textilis McClure. Molecules, 17(10), 12297-12311. https://doi.org/10.3390/molecules171012297

Xu, X., Zhou, G., Du, H., \& Partida, A. (2012). BamBoo forest change and its effect on Biomass carBon stocks: a case study of anji county, Zhejiang province, china. Journal of Tropical Forest Science, 426-435.

Yang, Y., \& Hui, C. (2010). China's bamboo-culture/resources/cultivation/utilization. Technical Report-International Network for Bamboo and Rattan (INBAR)(33). http://www.inbar.int/wp-content/uploa..

Yoo, J. J., Divita, L., \& Kim, H. Y. (2013). Environmental awareness on bamboo product purchase intentions: do consumption values impact green consumption? International Journal of Fashion Design, Technology and Education, 6(1), 27-34. https://doi.org/10.1080/17543266.2012.758318 


\section{Copyrights}

Copyright for this article is retained by the author(s), with first publication rights granted to the journal.

This is an open-access article distributed under the terms and conditions of the Creative Commons Attribution license (http://creativecommons.org/licenses/by/4.0/). 